\title{
SOME OBSERVATIONS ON TOBACCO BREEDING
}

\author{
W. W. GarNer \\ Washington, D. C.
}

Where it is desired to work with self-fertilized species the tobacco plant, on account of its habits of growth, the ease with which crossing is effected, the exceedingly large number of seed obtained from a single plant, etc., is particularly attractive for the experimental plant breeder. For the practical breeder, however, the case is quite different. The main purpose of the present paper is to call attention to some of the limitations of practical tobacco breeding, as well as to point out some of the serious difficulties met with in attempts to develop new or improved commercial types of tobacco, as gathered from observation extending over the last half dozen years. The writer is of the opinion that during the last decade the subject of practical plant breeding has been somewhat overdone, in the sense that there has been an undue concentration of effort on obtaining immediate results without adequate consideration of the underlying principles involved. As a consequence one might well question whether the results obtained are commensurate with the enormous amount of work which has been - done. It hardly seems likely that there will be more than occasional cases of conspicuous success mingled with the flood of failures until we have more definite knowledge of fundamental principles on which to build systematic methods of practical breeding. At any rate, we can safely say that this condition of affairs holds good in the case of tobacco breeding.

\section{RELATION OF ENVIRONMENT TO THE DEVELOPMENT OF THE TOBACCO PLANT}

We would call attention particularly to the failure of many plant breeders, especially in dealing with the practical phases of the subject, to give proper consideration to the matter of environment. It is a simple matter to draw theoretical distinctions between fluctuations and inherited characters, but in practice the characters which it is sought to improve are.in most cases those which are greatly influenced by environment. We need to know, first of all, therefore, something as to the relation of environment to plant growth, with respect to those characters concerned in the breeding problem. To expect to develop a thin cigar-wrapper type of tobacco on a heavy, clay soil is very much the same as expecting water to flow up hill by gravity. 


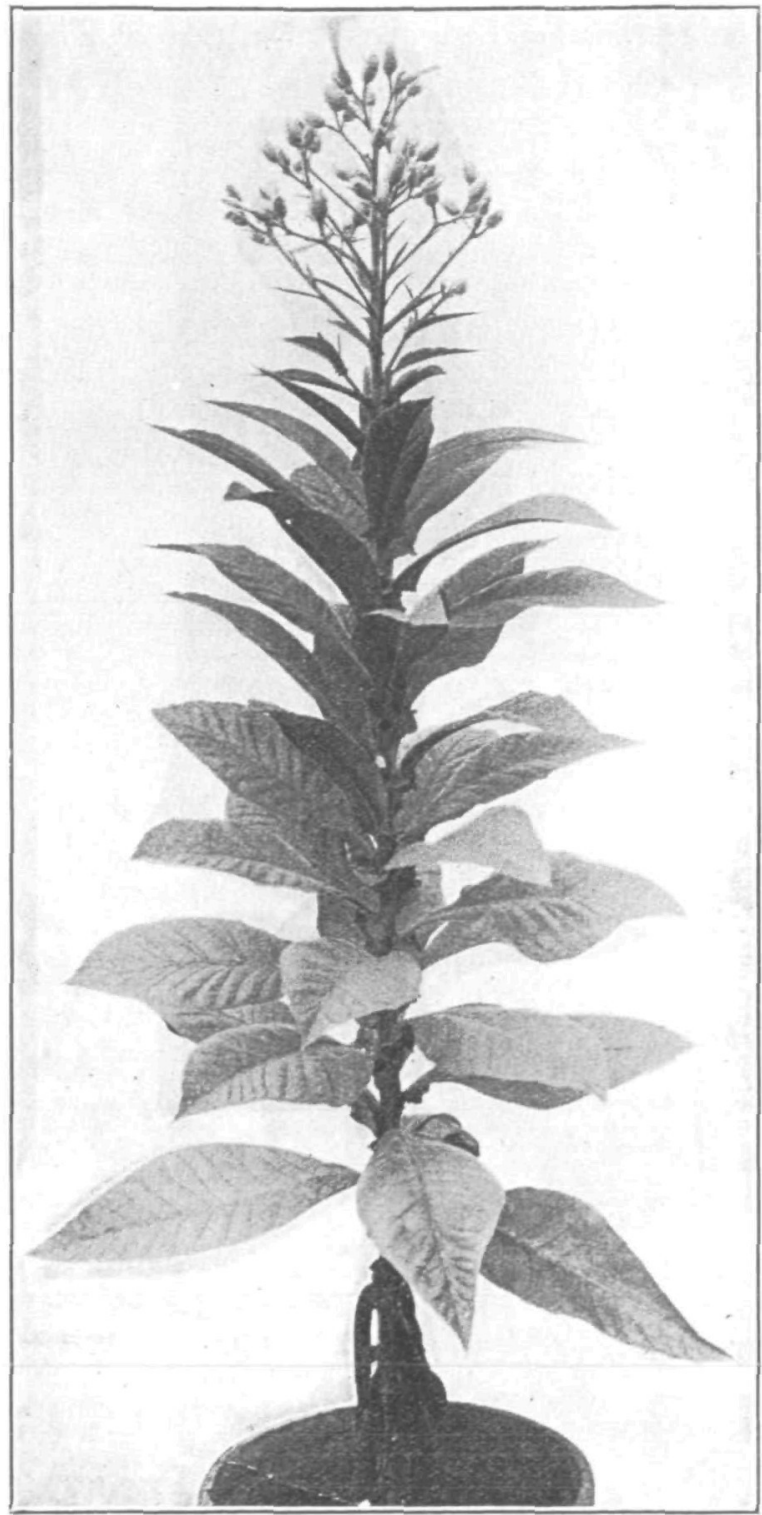

Fia. 1. Martuand Mammoth Tobacco.

Produced by crossing two types of Maryland tobacco. This type ts the same as shown in fig. 2. When grown in small pots with reduced water supply abundance of seed are produced and the leaves are greatly reduced in number and size and are much narrower. 
After having delimited the problem in breeding so as to bring it into. reasonable harmony with the influences of environment, it is clear that in order to secure a reliable measure of the results obtained the environmental factors must be eliminated. The plant breeder is frequently content to compare the behavior of, say, a half-dozen individuals of several varieties, types, or strains, grown on the same plot of soil and during the same season, with respect to such characters or qualities as yield, height of plant, etc., whereas it is a perfectly wellestablished fact that it is very difficult, and often impossible, to secure even approximate uniformity in environment. We would emphasize the fact that in practice uniformity in environment cannot be attained, and hence the misleading effects of fluctuations can only be eliminated by dealing with sufficiently large numbers of individuals and by duplicating or repeating the tests. Figs. 1 and 2 are presented as illustrating the extent to which environment may modify habit of growth without breaking the type. The so-called Maryland Mammoth, shown here and referred to more fully in succeeding paragraphs, normally forms upwards of 100 leaves and continues to grow until frost without showing any indication of blooming. By growing in a small pot with reduced water supply the shape, size, and number of leaves are radically changed and the plants bloom freely, finally setting an abundance of perfectly developed seed.

In the case of practical tobacco breeding the environmental effects are of extraordinary importance for several reasons. The leaf constitutes the portion of the plant which is of commercial importance, and leaf development is, of course, greatly influenced by environment. Again, the commercial requirements are very different for the different classes and types of tobacco, and these differences have their origin for the most part in the varied soil and climatic conditions under which the several types are produced. Furthermore, quality, which, in the last analysis, is dependent on chemical composition, is usually paramount to yield, and environment here plays a subtle but dominating rôle. The characteristic properties or qualities of a given commercial type of tobacco are the combined product of heredity and environment, and of these two factors it must be conceded that environment is the more important. Connecticut Havana and Ohio Zimmer Spanish are two well-known commercial "varieties" which are used for very different purposes and, when grown in their respective native regions, are absolutely different in those characteristics on which depend the commercial value of cigar tobaccos. And yet, as Houser has pointed out, when these two varieties are grown side by side, it 




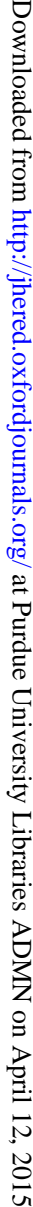

Fig. 2. Magyland Mammoth Tobacco.

Produced by crossing two types of Maryland tobacco, illustrating effect of change In environment on habits of growth. This type ts the same as shown in fig. 1. Under normalcondittons it continues to grow till frost without blooming, forming upwards of 100 leaves. 
is impossible to distinguish the one from the other! The tobacco breeder who overlooks these significant facts is likely to waste his efforts.

The best available evidence gathered from the experience of growers in the various tobacco districts, from the above mentioned viewpoint, seems to lead to the inevitable conclusion that there is no true line of demarcation between inherited characters and fluctuations with respect to many characters of commerical significance; in other words, there appears to be a progressive, cumulative effect of environment which represents a more or less gradual readjustment to changed environmental conditions. It must be said, howeyrer, that direct experimental evidence on the subject is wanting.

With respect to the breaking of type, that is, the production of mutations, by change of environment the evidence in the case of tobacco is far from satisfactory, mainly for the reason that where distinct strains have been isolated there is generally no certainty that the original stock was not mixed. We do not know of a case where distinct strains have been obtained from an authentic pure line as a result of change of environment. We have, however, one case where a Connecticut type which, although showing unmistakably the earmarks of a hybrid, is apparently uniform in habits of growth in its native region but which broke into several distinct forms when grown in Pennsylvania. The writer and assistants now have in progress a series of experiments with several pure strains from which it is hoped to secure more definite information regarding (1) the effect of environment on specific habits of growth and properties of the leaf, (2) the cumulative effects, if any, of environment, (3) the effect of environment on breaking the type. On the last-mentioned point it may be said that the evidence from the first year's work is purely negative.

- OUR PRESENT KNOWLEDGE OF TOBACCO BREEDING

Inbreeding.-Tobacco is a typically close-fertilized plant and it is perhaps not surprising to find that continued inbreeding, so far as it has been pushed, has given no indication whatever of causing deterioration. A number of types have been inbred by growing the seed under bag for six to eight years without any observable change in vigor or habits of growth.

Coninued selection.- It is undoubtedly true that tobacco is occasionally cross-fertilized and mixed types are frequently found in commercial crops. It is an extremely simple matter to select out the 
more desirable forms with respect to productiveness and habits of growth and to isolate these by saving the seed under bag. At the present time, however, we have no evidence that, isolation of these homozygous forms having been once effected, any further improvement can be brought about by continued selection within these strains.

Hybridization.-East has shown that the first generation of hybrids between different species of Nicotiana may or may not show increased vigor as compared with the parents and that the same holds true in the case of crosses between different varieties or strains of tabacum, the determining factor, of course, being the degree of heterozygosis, which may or may not be correlated with external or visible differences in form. We may say, therefore, that hybridization of our commercial types of tobacco usually, but not always, results in increase of vigor in the $F_{1}$ generation. It has been shown that the increase in vigor is expressed mainly in greater root development, longer internodes, and more rapid growth. It will be seen that these characters do not. necessarily denote increase in productiveness, but there is abundant evidence that increased leaf development, that is, increased productiveness, is usually obtained, although it must be admitted that there is a dearth of reliable statistical data. Houser has pointed out the possibility of utilizing first-generation hybrids for the growing of tobacco commercially, and where increased productiveness is the primary aim it would seem that this method is practicable; but it is to be remembered that commercial requirements are vastly different for the various types of tobacco, and in many cases yield is secondary to quality. In such cases it must first be shown that there is uniformity of quality in the $F_{1}$ hybrids and that the quality is at least as good as that of the types now in use. It must be understood that uniformity in characters observable in the field by no means indicates uniformity in those characteristics on which commercial value depends.

Since whether or not there is actual heterozygosis, rather than external differences of form, determines the increase in vigor, it cannot be known in advance that any particular cross will show increased vigor. In other words, we cannot by mere inspection of the parent plants determine their relationship in this particular. Mr. E. K. Hibshman working in Pennsylvania found, for example, that two strains of the same type, apparently very closely related, the only known difference being that they had been grown on somewhat different soil types, gave, when crossed, a marked increase in vigor. In many cases the

a Bur. of Pl. Ind., Bulletin 244. 
$F_{1}$ generation is intermediate between the parent types with respect to habits of growth, but this is not always true. The $F_{1}$ generation of a cross between Little Oronoco and White Burley was indistinguishable in all respects from the Oronoco parent, except that the plants showed very clearly increase in vigor. By crossing two types of Maryland tobacco Mr. D. E. Brown obtained the so-called Maryland Mammoth, possessing remarkable vegetative vigor and not closely resembling either parent. This type has remained fixed from the beginning and under ordinary field conditions continues to grow till frost without blooming, often producing as many as 150 leaves. The root stock, when transplanted under glass, sends out suckers which set seed readily and; as shown in fig. 2, the original plant can ke made to bloom under certain conditions.

Experience has shown that the production of new, stable forms by hybridization in the vast majority of cases involves, at best, careful and long-continued selection. As a matter of fact, we are unable at the present time to point to a single instance in which hybridization and selection have produced a type definitely known to be fixed with respect to characters susceptible of measurement. Nevertheless, hybrids have been developed which show sufficient uniformity to warrant their commercial use where the requirements as to quality are not particularly exacting. If the tobacco breeder's problems were limited to the scope of those for most crop plants, namely, increase in vield and, perhaps, improvement in habits of growth, disease resistance, etc., the field would be far more promising, but the complications introduced by the question of quality of the cured leaf, which are discussed in succeeding paragraphs, make it very doubtful whether much can be accomplished in the betterment of the more highly specialized phases of the industry by hybridization and selection.

Breeding for nicotine content.-Nicotine is the characteristic alkaloid of tobacco to which is due primarily the physiological effects of the leaf but which has little to do with the flavor or aroma. The quantity of nicotine contained in tobacco can be readily determined, and since many individuals who use tobacco prefer it in very mild form the writer some years ago undertook the development of a type of cigar filler leaf low in nicotine content. It was early recognized that the production of nicotine in tobacco is greatly influenced by soil and climatic conditions and also by cultural methods, so that these factors must be rigidly controlled in dealing with the breeding phases of the problem. As a result of several years' work, we have obtained a type of Cuban tobacco of which the average nicotine content for the leaves 
of 30 individuals grown in east Texas in 1910 was only 0.34 per cent, the highest figure for any individual being 0.50 per cent and the lowest 0.18 per cent. Cigars made from this type are the mildest of any we have ever tested. The nicotine content of our standard filler types usually runs from 2 to 5 per cent.

On account of the increasing demand for nicotine as an insecticide, it is not unlikely that tobacco could be profitably grown solely for obtaining this constituent, provided means can be devised for increasing the amount contained in the plant. We have recently undertaken experiments with a view to developing types characterized by high nicotine content, and this problem is perhaps simpler than that discussed in the preceding paragraph, for the reason that no attention need be paid to the quality of the leaf.

\section{TOBACCO BREEDING FROM THE GROWER'S STANDPOINT}

Attention has already been called to the fact that the tobacco breeder must consider the quality of the cured leaf, as well as the productiveness and other visible habits of growth, and quality is frequently paramount to productiveness so far as financial returns are concerned. Unfortunately, quality is often more or less antagonized by those factors tending toward increased productiveness, and this matter is of such vital importance that we have thought it desirable to bring out clearly the two distinct phases of practical tobacco breeding.

We have abundant evidence that such characters as shape, size, and number of leaves, extent of suckering, and length of internode can be largely controlled by well-directed efforts in hybridization and relection, and, although it is extremely difficult to obtain stable recombinations, this can frequently be sufficiently approximated with respect to some of the more important characters to make the new forms very desirable from the standpoint of the grower. An excellent illustration in point is the Halladay type, described by Shamel, ${ }^{\mathbf{b}}$ which is in many respects an ideal type, from the grower's point of view, 'for the production of cigar-wrapper leaf. In general habits of growth and productiveness it is far superior to either parent, possessing the desirable characters of both, is perfectly uniform in growth, so far as can be observed by simple inspection, and; as a whole, presents a handsomer appearance in the field than any other tobacco the writer has observed. The weak points of this type as regards quality are referred to under the next heading.

b A. B. A., v1, p. 273. 
Some of the characters relating to habits of growth, more particularly shape, size, and venation of leaf, are of special interest to the manufacturer, while others, such as number of leaves, length of internode, extent of suckering habit, and root system are of importance only to the grower. These latter characters are of importance with reference to yield, pole-sweat in curing, labor required, and vigor of growth and protection against unfavorable weather conditions, respectively.

The plant breeder must keep clearly in mind that the commercial requirements, as well as the problems of interest to the grower alone, are quite different for the several classes of tobacco, and he must, first of all, acquaint himself thoroughly with the requirements for the particular class of tobacco with which he proposes to deal. This done, by making a wise selection of parent stocks and confining himself to only a very few characters for improvement, he may hope to secure new forms which are desirable from the grower's standpoint alone, or from the manufacturer's point of view, as well, with respect to characters observable in the field. But we shall see that in some cases, at least, this is merely beginning the problem.

\section{TOBACCO BREEDING FROM THE MANUFACTURER'S STANDPOINT}

The financial returns from a crop of tobacco necessarily depend much on the yield obtained, but, as a rule, quality is of even greater importance in this connection and by quality is meant that of the cured leaf and not that of the leaf as it matures in the field. Quality, as the term is used commercially, is composed of such elements as color, texture, elasticity, aroma, flavor, body or thickness of leaf, and capacity for burning freely. The grower is naturally interested in both yield and quality, while the manufacturer is concerned only with quality. Maximum yield is frequently incompatible with highest quality, so that the interests of the grower and the manufacturer aro to some extent antagonistic, but in the end the grower must meet as far as practicable the demands of the manufacturer.

The plant breeder must of necessity keep in mind the requirements of the manufacturer as well as those of the grower, but unfortunately there is no means of judging in the field most of the important elements of quality, and herein lies a difficulty almost insuperable to the prac. tical breeder. $\mathrm{He}$ is in the dark as to quality while making his selections for characters observable in the field, and where there are a considerable number of independent elements constituting quality it 
is readily seen what slight probability there is of obtaining by mere chance the desired combination, even when a sufficiently large progeny is grown to make it likely that this combination is present. Moreover, the matter is further complicated by the fact that in certain cases the leaf cannot be matured and cured under normal conditions if seed of the individual is to be obtained.

There is no demand for novelties in the tobacco industry, so that any new type produced must resemble more or less closely in the important elements of quality the standard types of the particular class in question. So far as known to the writer, no one has thus far succeeded in producing by hybridization a new type acceptable to the trade as regards quality in those classes of tobacco, such as cigarwrapper leaf, for example, for which commercial requirements are very exacting. We have mentioned the Halladay as a conspicuous example of a type developed by hybridization which is almost ideal from the grower's standpoint, since it is decidedly superior to the standard Connecticut types with respect to vigor, size, shape, and number of leaves produced. The fundamental objection to this type is that the cured leaf departs from the standard requirements in such elements of quality as color, texture, and elasticity. The variable qualities of cured tobacco, such as color, aroma, elasticity, etc., of course depend on differences in chemical composition, but these differences are, for the most part, of such complex and obscure nature that they cannot be determined by methods of analysis now available. It is interesting to note in this connection, however, that the Halladay tobacco is markedly low in starch content, with a corresponding increase in organic nitrogenous constituents, as compared with standard Connecticut types such as the Connecticut Havana.

It has been pointed out that, in general, environmental factors exert a controlling influence in the development of most of the important elements of quality. We may recall, for example, that the world's standard of excellence for cigar-filler leaf is produced only in a very small area in Cuba known as the Vuelta Abajo district, and growers throughout Cuba recognize the fact that environment is the controlling factor in producing this renowned tobacco, practically no attention being given to the matter of seed. If there be any truth in the conception of the cumulative effects of environment, it would seem possible that growing a new, fixed type, which is deficient in quality of cured leaf, such as the Halladay, for several generations in a particular environment would result in its acquiring, to some degree at least, the quality characteristic of the tobaccos produced in that region. 
Connecticut Havana and Connecticut Broadleaf are often grown on the same.soil, and while distinct differences in quality between the two types are always observable, they are sufficiently similar in essential points to warrant their being used for the same purposes.

We have seen that the opportunities for developing improved types by hybridization are limited in dealing with those classes of tobacco in which several elements of quality are of the first importance, because of the difficulties in the way of systematic selection with respect to these elements of quality. The situation is more encouraging, however, in the case of other classes of tobacco, in which the requirements as to quality are less exacting and in which, consequently, increased yield assumes greater importance. We may mention Ohio cigarfiller leaf types developed through hybridization by Prof. A. D. Selby and assistants, in coöperation with the Bureau of Plant Industry, as cases in which increased productiveness has been obtained without prejudice, it is believed, to trade requirements. Again, we have developed in Maryland new types of increased productiveness by crossing the native types with Connecticut Broadleaf and with White Burley. These new types are sufficiently uniform in habits of growth, and meet commercial requirements well enough, to warrant their acceptance by the trade, and they are now being grown on an extensive scale.

\title{
CERTAIN RESULTS IN OHIO TOBACCO BREEDING
}

\author{
True Houser \\ Germantown, $O$.
}

It is the intention in this brief paper to cover but a few of the many phases of recent progress in the tobacco breeding work which has been carried on since 1903 by the Ohio Agricultural Experiment Station at the Southwestern Sub-Station located at Germantown, in the heart of the Miami Valley cigar filler district.

During this period of time over 300 hybrids have been made and from the careful breeding out of the older ones a number of apparently valuable new varieties have been obtained, some of which are just beginning to be extensively grown by the farmers of this district. Many other types of later development give promise of still greater excellence, but are not yet sufficiently fixed or have not been tested long enough to warrant distribution. Year by year the hybrid work 